\title{
MicroRNA-9a ensures the precise specification of sensory organ precursors in Drosophila
}

\author{
Yan Li, ${ }^{1}$ Fay Wang, ${ }^{1}$ Jin-A Lee, and Fen-Biao Gao ${ }^{2}$ \\ Gladstone Institute of Neurological Disease and Department of Neurology, University of California at San Francisco, \\ San Francisco, California 94158, USA
}

\begin{abstract}
MicroRNAs (miRNAs) have been implicated in regulating various aspects of animal development, but their functions in neurogenesis are largely unknown. Here we report that loss of miR-9a function in the Drosophila peripheral nervous system leads to ectopic production of sensory organ precursors (SOPs), whereas overexpression of miR-9a results in a severe loss of SOPs. We further demonstrate a strong genetic interaction between miR-9a and senseless (sens) in controlling the formation of SOPs in the adult wing imaginal disc. Moreover, miR-9a suppresses Sens expression through its 3' untranslated region. miR-9a is expressed in epithelial cells, including those adjacent to SOPs within proneural clusters, suggesting that miR-9a normally inhibits neuronal fate in non-SOP cells by down-regulating Sens expression. These results indicate that miR-9a ensures the generation of the precise number of neuronal precursor cells during development.
\end{abstract}

[Keywords: MicroRNA; SOP; Senseless; Drosophila; PNS]

Supplemental material is available at http://www.genesdev.org.

Received July 6, 2006; revised version accepted August 22, 2006.

The peripheral nervous system (PNS) is essential for animals to detect and relay environmental stimuli to central neurons for information processing. It is largely unknown what ensures the development of precise numbers of sensory organs for a particular external sensory cue. The Drosophila PNS has been used as an excellent model system for dissecting the genetic programs that control sensory organ formation (Ghysen and DamblyChaudiere 1993; Jan and Jan 1993; Modolell 1997). In embryonic abdominal segments, external sensory (ES) organs and chordotonal $(\mathrm{CH})$ organs contain single-dendrite neurons associated with support cells and function in receiving mechanical stimuli (Campos-Ortega and Hartenstein 1985; Ghysen et al. 1986). In contrast, multidendritic (MD) neurons elaborate highly branched dendrites underneath the epidermis (Bodmer and Jan 1987; Gao et al. 1999) that probably function as stretch, touch, or other sensory receptors (Ainsley et al. 2003; Liu et al. 2003; Tracey et al. 2003). In adult flies, most external sensory organs have one neuron, one hair cell, and a few support cells (Campos-Ortega and Hartenstein 1985).

Precise numbers of sensory organs are generated through similar developmental processes in embryos and adults (Campos-Ortega and Hartenstein 1985). For ex-

\footnotetext{
${ }^{1}$ These authors contributed equally to this work.

${ }^{2}$ Corresponding author.

E-MAIL fgao@gladstone.ucsf.edu; FAX (415) 355-0824.

Article published online ahead of print. Article and publication date are online at http://www.genesdev.org/cgi/doi/10.1101/gad.1466306.
}

ample, in embryonic/larval abdominal segments, each dorsal cluster contains four ES organs and eight MD neurons. Some ES neurons are generated from sensory organ precursors (SOPs) that also produce MD neurons (ESMD lineage), while other lineages produce ES but not MD neurons (Brewster and Bodmer 1995; Vervoort et al. 1997). Adult flies have four macrochaetes on the notum and a well-defined number of sensory bristles on the wing margin. All cells in each adult sensillium are generated from a single SOP in two or three rounds of asymmetric cell division (Hartenstein and Posakony 1989; Bardin et al. 2004).

The selection of SOPs from early ectoderm begins with the proneural cluster, which consists of a small number of cells that express proneural genes encoding the basic helix-loop-helix (bHLH) proteins (Achaete, Scute, Asense, Atonal, and Amos), rendering those cells competent to develop into SOPs (Romani et al. 1989; Cubas et al. 1991; Skeath and Carroll 1991; Jarman et al. 1993; Ruiz-Gomez and Ghysen 1993; Goulding et al. 2000; Huang et al. 2000). It is thought that the cells with the highest level of proneural proteins are selected as SOPs, which express a higher level of Delta and activate Notch in neighboring cells (Goriely et al. 1991; Artavanis-Tsakonas et al. 1999). Activation of Notch initiates a signaling cascade in which Suppressor of hairless [Su(H)] and Enhancer of split [E(spl)] complexes are involved to suppress neuronal fate in non-SOP cells (Knust et al. 1992; Schweisguth and Posakony 1992). 
One of the genes activated by bHLH proteins, senseless (sens), encodes a transcription factor with four zinc fingers whose expression is dynamically regulated within the proneural clusters (Nolo et al. 2000). Within the proneural cluster, a high level of Sens is required to up-regulate and maintain the proneural gene expression in SOPs (Nolo et al. 2000), while a low level of Sens represses the transcription of proneural genes in adjacent cells (Jafar-Nejad et al. 2003). This dual function of Sens as an activator or suppressor suggests that the proper level of Sens is required to control the formation of the precise number of SOPs. However, how differential expression levels of Sens in SOPs and adjacent cells are ensured remains unknown.

In recent years, post-transcriptional regulation by microRNAs (miRNAs) has emerged as an important mechanism for controlling gene expression in animal development (Carrington and Ambros 2003; Bartel 2004; He and Hannon 2004; Alvarez-Garcia and Miska 2005; Carthew 2006). miRNAs are endogenous noncoding small RNAs 21-23 nucleotides (nt) in length. Several miRNAs have been implicated in nervous system development, with roles ranging from regulating left/right neuronal asymmetry in Caenorhabditis elegans, photoreceptor formation in Drosophila, and brain morphogenesis in zebrafish, to neuronal differentiation in mammals (Johnston and Hobert 2003; Chang et al. 2004; Giraldez et al. 2005; Li and Carthew 2005; Vo et al. 2005; Krichevsky et al. 2006; Schratt et al. 2006). However, the precise roles of miRNAs in early neurogenesis have not been studied yet. Moreover, only a few miRNAs have been studied using loss-of-function approaches in Drosophila (e.g., Brennecke et al. 2003; Xu et al. 2003; Kwon et al. 2005; Li and Carthew 2005; Sokol and Ambros 2005; Teleman et al. 2006).

Here, through both loss-of-function and gain-of-function in vivo analyses, we found that $m i R-9 a$ is required to ensure the generation of precise numbers of sensory organs in Drosophila embryos and adults. To accomplish this regulatory function, $\mathrm{miR}-9 a$ down-regulates the expression of Sens through its 3' untranslated region (UTR) to ensure the differential expression of Sens in SOPs and adjacent epithelial cells. These findings provide new evidence that miRNAs function at the translational level to ensure the appropriate level of gene expression during different developmental processes.

\section{Results}

Generation of miR-9a mutant flies

To understand the roles of miRNAs in neural development, we chose Drosophila miR-9a for further analysis for the following reasons. First, the Drosophila homolog of the human fragile $\mathrm{X}$ mental retardation protein affects the formation of terminal dendritic branches (Lee et al. 2003) and is associated with miRNAs and the RNA-induced silencing complex, implicating miRNAs in human mental disorders (Caudy et al. 2002; Ishizuka et al. 2002). Second, miR-9a is one of the miRNAs that are specifically and highly expressed in the mammalian brain, suggesting a unique role in neural development and/or function (Lagos-Quintana et al. 2002). Third, mature $\operatorname{miR}-9 a$ is $100 \%$ conserved at the nucleotide level from flies to humans (Fig. 1A; Aravin et al. 2003), indicating an evolutionarily conserved function. Moreover, in contrast to the mouse genome, which has three $m i R$ $9 a$ precursors located on different chromosomes (LagosQuintana et al. 2002), the Drosophila genome has only one (Aravin et al. 2003; Sempere et al. 2004), providing a good opportunity to study the function of this miRNA.

The Drosophila miR-9a precursor is located on the left arm of the third chromosome $76 \mathrm{~B} 7,10 \mathrm{~kb}$ to the right of gene CG9300 and $6.4 \mathrm{~kb}$ to the left of gene CG9262 (Fig. $1 B)$. To generate loss-of-function mutants of $m i R-9 a$, we used ends-out homologous recombination (Gong and Golic 2003) to replace the 78-nt long $m i R-9 a$ precursor DNA sequence with the white gene (Fig. 1C). To screen for potential miR-9a mutants, we used PCR analysis with two primers flanking $m i R-9 a$. These primers produced a $0.5-\mathrm{kb}$ fragment when wild-type genomic DNA was used as the template and a 4-kb fragment if miR-9a was replaced by white (Fig. 1D). From two independent gene-targeting experiments, we generated five mutant lines in which homologous recombination occurred at the miR-9a locus (Fig. 1D). To confirm that the expression of $m i R-9 a$ was indeed abolished in mutants, we performed Northern blot analysis that showed the absence of $m i R-9 a$ in all five mutant lines (Fig. 1E). Lines J22 and E39, generated from two independent targeting events, were selected for further analysis.

Loss of miR-9a function results in ectopic sensory neurons in Drosophila embryos and larvae

Both $\operatorname{miR}-9 a^{J 22}$ and $\operatorname{miR}-9 a^{E 39}$ mutant flies developed to adulthood at the expected Mendelian ratio and were fertile, suggesting that miR-9a activity is not essential for survival or fertility. However, when we examined the morphology of PNS neurons, we found unexpectedly that some of the MD neurons were duplicated. Normally, Drosophila embryos and larvae have 12 sensory neurons in each dorsal cluster in the abdominal segments (Fig. 2A), including eight MD neurons. At the larval stage, each MD neuron has a unique dendritic branching pattern that is fairly consistent from segment to segment and among different animals (Bodmer and Jan 1987; Grueber et al. 2002; Sweeney et al. 2002). Using a specific driver, Gal4 ${ }^{221}$, we examined two MD neurons, ddaE and ddaF (Sweeney et al. 2002), which extend smooth dendrites toward the posterior and anterior, respectively (Fig. 2B). Twenty-nine percent of $m i R-9 a^{J 22}$ $(n=62)$ and $37 \%$ of $m i R-9 a^{E 39}$ mutant third instar larvae $(n=27)$ contained an extra ddaE or ddaF neuron in one or two but not other hemisegments (Fig. 2C,D), while none of the wild-type larvae had this phenotype $(n=24)$. A similar phenotype was also seen in vpda, a ventral MD neuron that also extends simple and smooth dendritic branches (Supplementary Fig. S1).

The frequent observation of two-cell clones generated 
A

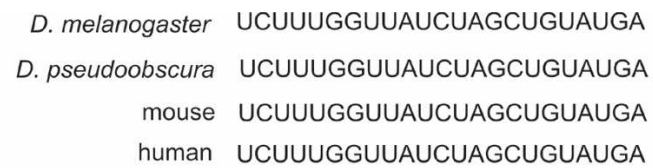

B

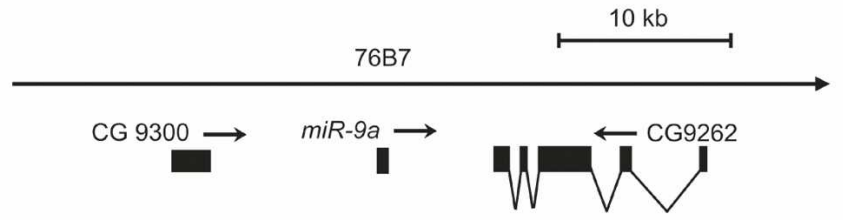

C

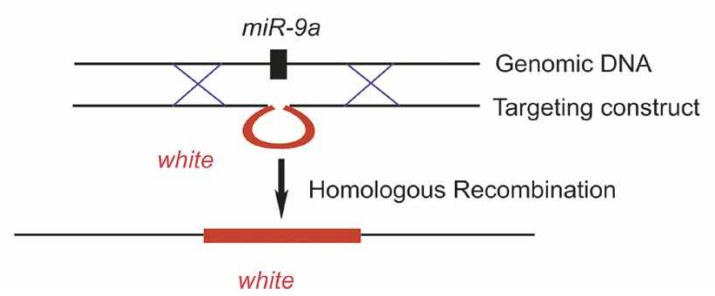

D

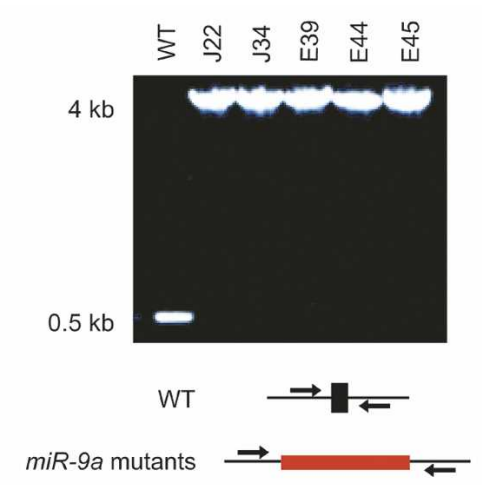

$\mathrm{E}$

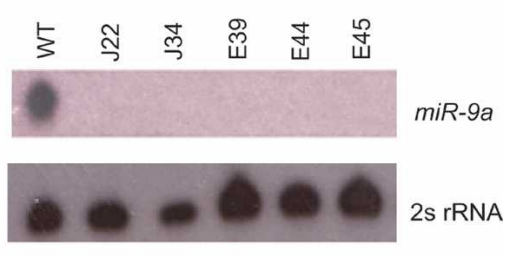

Figure 1. Generation of miR-9a loss-of-function mutant flies. (A) Nucleotide sequence alignment of miR-9a among different species. $(B)$ The cytological location of miR-9a in the Drosophila genome. $(C)$ The ends-out recombination approach was used to replace the 78-nt long miR-9a precursor with the white gene. $(D)$ The miR-9a mutant lines were identified by PCR analysis using primers flanking the miR-9a locus. $(E)$ Northern blotting analysis confirmed that miR-9a was absent in the mutant lines. The same Northern membrane was probed with a 2 s rRNA probe as the loading control.

by mosaic analysis with a repressible cell marker (MARCM) (Lee and Luo 1999) that contained an ES neuron and either a ddaE neuron or a ddaF neuron (Sweeney et al. 2002) suggests that $\mathrm{ddaE}$ and ddaF neurons are generated from the ES-MD lineages. To examine whether the duplicated neurons in $\mathrm{miR}-9 a$ mutants resulted from cell fate transformation within the ES-MD lineage or from an ectopic SOP, we counted neurons and support cells of A5-A6 dorsal clusters in embryos. As shown by immunostaining, each wild-type dorsal cluster contained $12 \mathrm{Elav}^{+}$neurons (eight MD and four ES neurons) and eight $\mathrm{Cut}^{+} / \mathrm{ELAV}^{-}$cells (external cells, Fig. 2E). In the miR-9a mutant embryos, more cells were observed in some dorsal clusters. Among the four extra cells, there were two $\mathrm{Elav}^{+}$neurons accompanied by two $\mathrm{Cut}^{+} /$ $\mathrm{ELAV}^{-}$external cells (Fig. 2F), suggesting that an extra SOP was generated. These findings suggest that miR-9a affects the precise production of SOPs during Drosophila embryonic development.

To understand how miR-9a is involved in SOP specification, we performed in situ hybridization with a probe for the $m i R-9 a$ precursor. The earliest expression of $m i R$ $9 a$ was at stage 5 and was observed in all cells except most ventral cellular blastula (data not shown). After gastrulation at stage $7, \operatorname{miR}-9 a$ expression persisted in all epithelial cells except the ventral ectoderm (Fig. 2G). Ectodermal epithelial cells continued to express $m i R-9 a$, and at stage 10-13, strong expression of $m i R-9 a$ was seen at the ectoderm of the segmental boundaries and stomodeum (Fig. 2H). During this stage, embryonic PNS SOPs are derived from the epidermal cells. Consistently, we observed a similar embryonic expression of $m i R-9 a$ with a probe made out of the mature $m i R-9 a$ (data not shown), which was also reported independently during the course of our work by Stark et al. (2005).

\section{miR-9a controls the generation of sensory organs in adult flies}

The increased production of sensory neurons in $\operatorname{miR}-9 a$ mutant embryos/larvae prompted us to further examine the sensory organ formation in adult flies. Wild-type anterior wing margins have a fixed number of regularly spaced sensory bristles (Fig. 3A'). About $40 \%$ of $m i R-9 a$ mutants flies showed ectopic sensory bristles on anterior wing margins (Fig. 3B'), while flies overexpressing $m i R$ $9 a$ had a marked decrease in the number of bristles (data not shown). miR-9a mutant flies also exhibited a posterior wing margin defect, which was $100 \%$ penetrant (Fig. 3B). To confirm that the wing phenotype was caused by the loss of $\operatorname{miR}-9 a$ activity, we performed a genetic rescue experiment. Expressing the $m i R-9 a$ precursor by $v g$ Ga14, which drives gene expression in the thin strip of dorsal-ventral boundary of wing imaginal discs, in the miR-9a mutant background completely rescued the defects on posterior wing margins ( $n=152$, Fig. $3 C)$. The bristle defect on the anterior margin of $\operatorname{miR}-9 a$ mutants was also largely rescued (Fig. 3C').

Besides the wing phenotype, miR-9a mutant flies also displayed an ectopic production of sensory organs on the notum. Each SOP generates five different cells in two to three rounds of division to form an entire sensory organ on the notum (Fig. 4A). Wild-type flies have two scutellar bristles (Fig. 4B) on each heminotum, but $14.3 \%$ of 

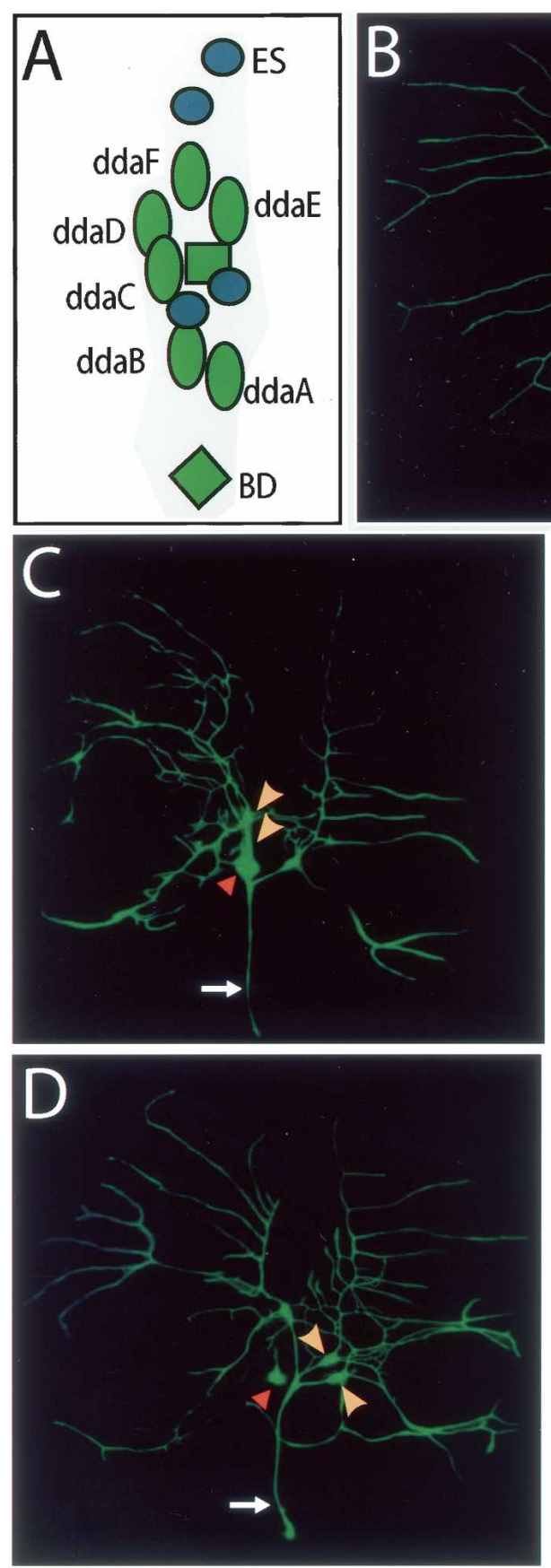
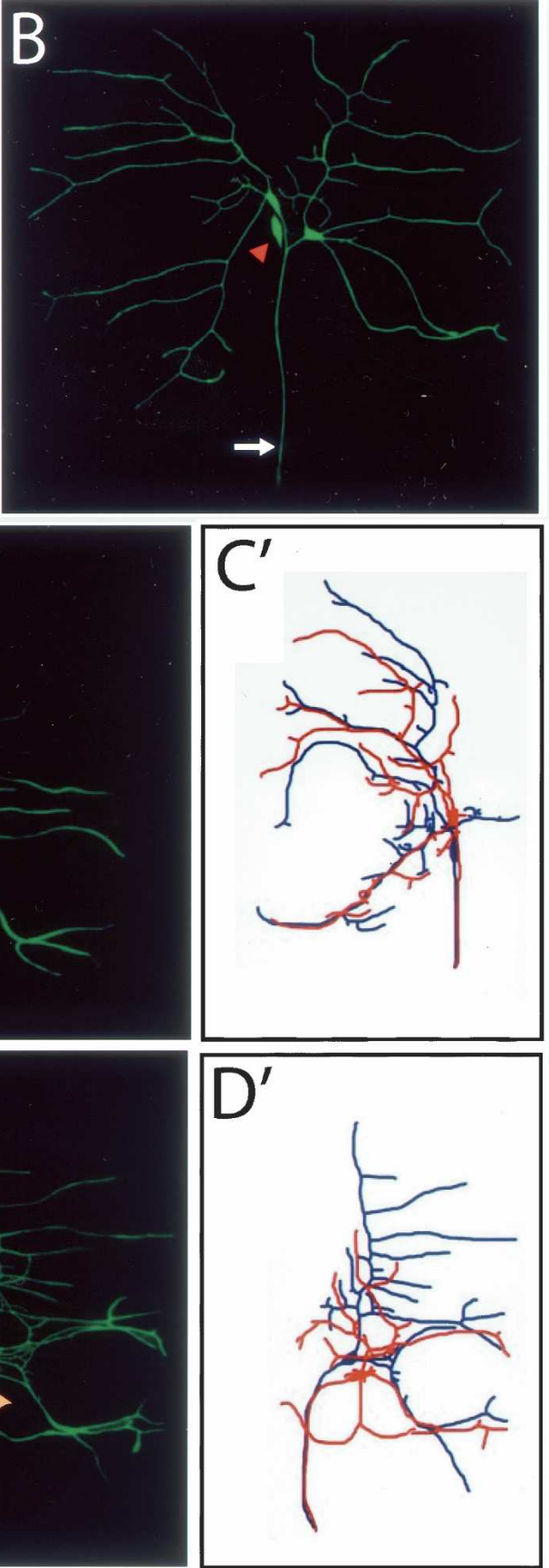
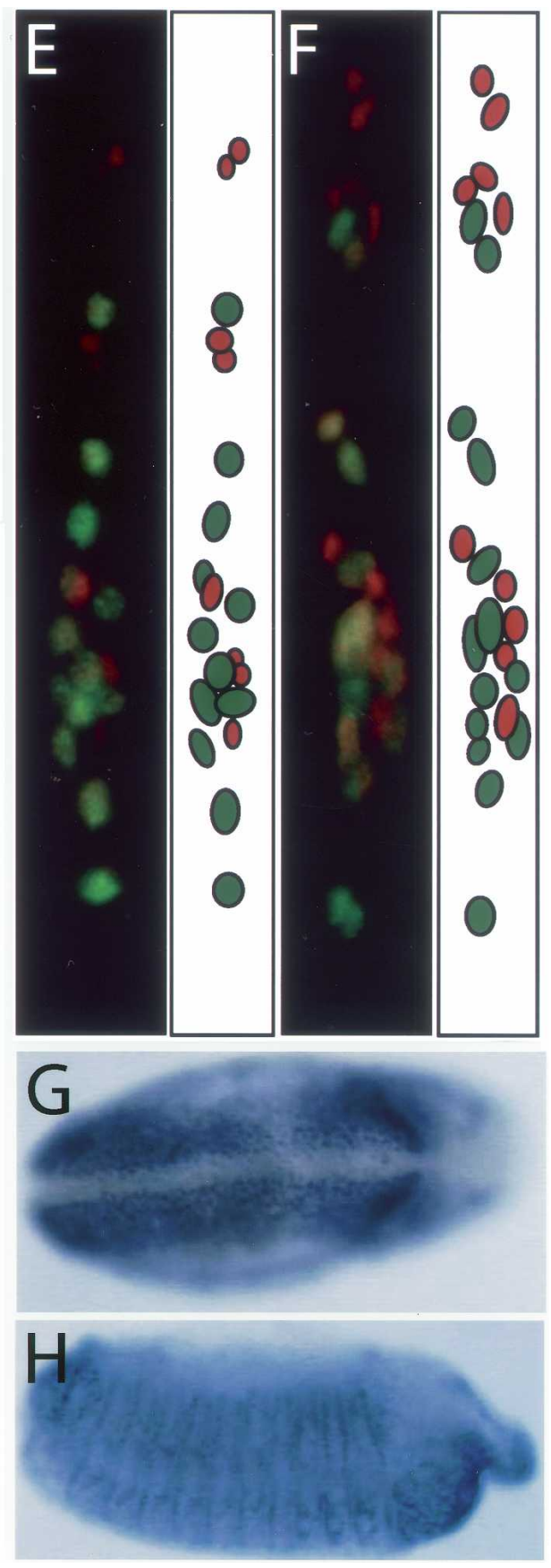

Figure 2. Loss of miR-9a activity resulted in the formation of ectopic sensory neurons in Drosophila embryos and larvae. (A) Schematic representation of the dorsal cluster sensory neurons in each abdominal hemisegment. $(B)$ Wild-type ddaE and ddaF neurons in third instar larvae are labeled by mCD8-GFP with Gal4 ${ }^{221}$. The white arrows in $B, C$, and $D$ indicate axons of these sensory neurons. The red arrowheads indicate ddaC neurons that are faintly labeled by GFP with Gal4 ${ }^{221}$. In miR-9a mutant larvae, duplicated ddaF $(C)$ and $\mathrm{ddaE}(D)$ neurons (yellow arrowheads) were observed with near normal dendritic branches (traced in $\left.C^{\prime}, D^{\prime}\right) \cdot(E, F)$ All the neurons of one dorsal cluster of stage 15 embryos were double-labeled with anti-ELAV (green) and anti-Cut (red) antibodies. (E) In wild-type embryos, there are $12 \mathrm{ELAV}^{+}$cells, including MD neurons and ES neurons, and eight $\mathrm{Cut}^{+} / \mathrm{ELAV}^{-}$support cells. $(F) \mathrm{A}$ miR-9a $a^{\text {I22 }}$ embryo with $14 \mathrm{ELAV}^{+}$cells and $10 \mathrm{Cut}^{+} / \mathrm{ELAV}^{-}$support cells. $(G, H)$ miR-9a expression is detected in epithelial cells in wild-type embryos with in situ hybridization. $(G)$ After gastrulation at stage 7, miR-9a expression persists in most epithelial cells except the ventral ectoderm. (H) At stage 12-13, miR-9a is expressed in the ectoderm, with higher levels at the segmental boundaries and stomodeum.

miR-9a mutant flies (14 out of 98) had three or four bristles (Fig. 4C) with accompanying shaft and socket cells (Fig. 4E). Conversely, flies overexpressing miR-9a in the notum region by ap-Gal4 had a severe loss of scutellar sensory organs (Fig. 4D). Like the wing margin phenotype, defects on the notum of miR-9a mutant could be 

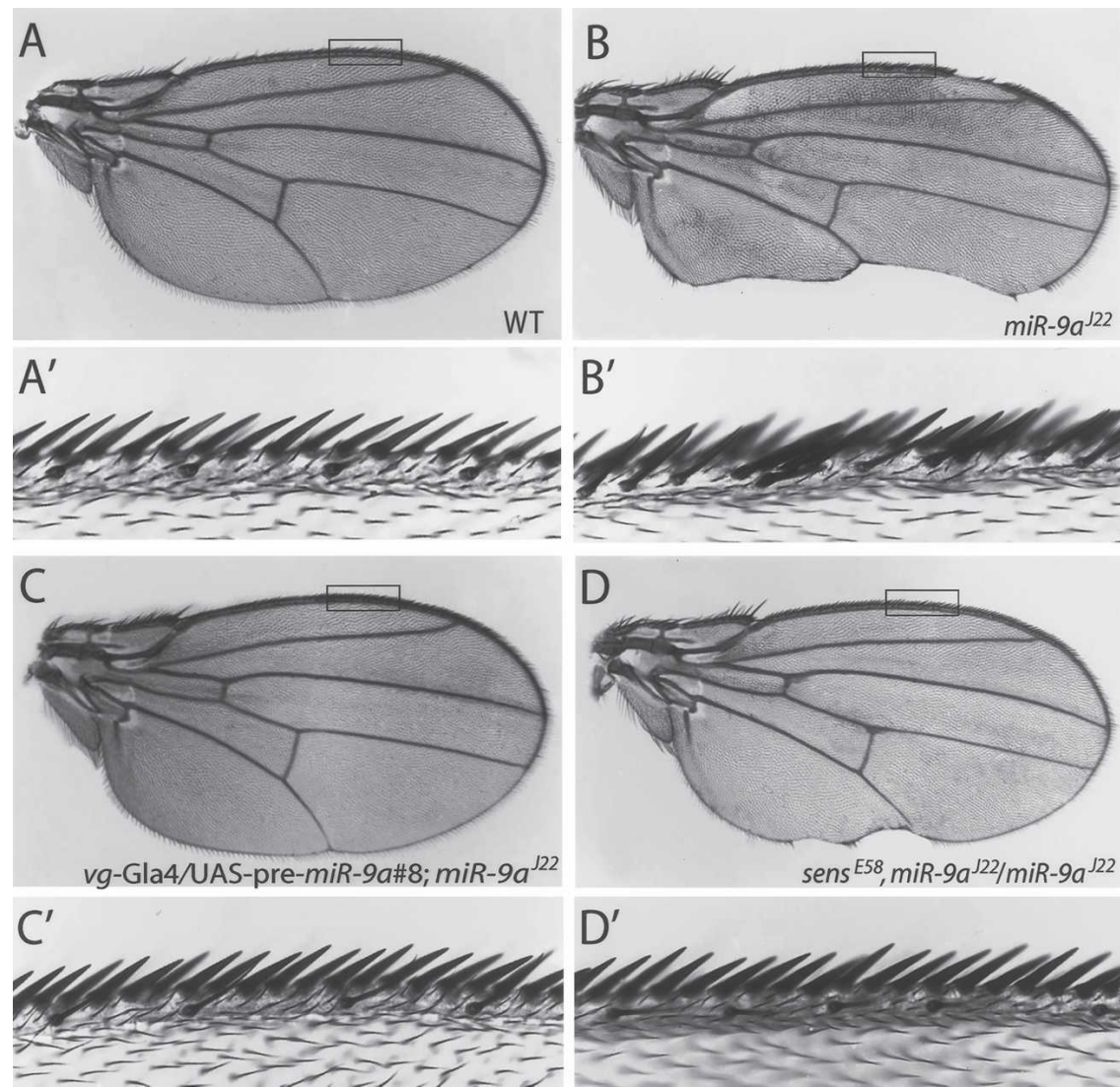

Figure 3. Wing margin defects in $m i R-9 a$ mutant flies. (A) A wild-type wing. The rectangle indicates the areas enlarged into $A^{\prime}$ (same for those in $\left.B-D\right) .\left(A^{\prime}\right)$ Sensory hairs on anterior wing margin are assembled in a regular pattern with four macrochaetes flanking one microchaete. (B) All miR-9a mutant flies lose the posterior wing margin, while the veins are normal in appearance. $\left(B^{\prime}\right)$ Ectopic sensory hairs on the anterior wing margin in $m i R$ $9 a$ mutants. $\left(C, C^{\prime}\right)$ The wing margin defects in miR-9a were rescued by expression of the wild-type miR-9a precursor (line \#8) with $v g$-Gal4 $(n=152) .\left(D, D^{\prime}\right)$ The wing margin defects of miR-9a mutants were suppressed by removing one copy of sens. sens ${ }^{E 58}$ was recombined with $m i R$ $9 a^{J 22}$ onto the same chromosome. rescued by expression of $\operatorname{miR}-9 a$ precursors using $V g$ Gal4 ( $n=152)$. To further demonstrate the bristle phenotype was due to increased number of scutellar SOPs in miR-9a mutants, we stained the notum with Elav antibody. We found that each ectopic bristle was also associated with an extra neuron (Fig. 4E), supporting our hypothesis that $m i R-9 a$ regulates the specification of SOPs during sensory organ development.

\section{miR-9a genetically interacts with sens}

The wing margin phenotypes of miR-9a mutant flies are remarkably similar to that seen in $\operatorname{Lyra}^{1}$ mutant flies, a gain-of-function mutant of sens, and in flies with forced expression of Sens in the wing (Nolo et al. 2001). Moreover, the sens 3'UTR contains miR-9a-binding sites (Stark et al. 2003), raising the possibility that Sens might be misregulated in $\operatorname{miR}-9 a$ mutant flies. To test this hypothesis, we performed genetic interaction studies. In a miR-9a $a^{222}$ homozygous mutant background, removing one copy of sens $\left(\operatorname{sens}^{E 58} /+\right)$ led to a substantial rescue of the wing margin defect. About $30 \%$ of these flies had wings indistinguishable from the wild type, while others lost only a smaller part of the posterior margin (Fig. 3D); the bristles on the anterior margin also resembled wild type (Fig. 3D'). In contrast, $100 \%$ of $m i R-9 a$ mutant flies had posterior wing margin defects (Fig. 3). These findings suggest that up-regulation of Sens is a key downstream event caused by loss of miR-9a activity.
To provide further evidence that $\operatorname{miR}-9 a$ regulates Sens during the sensory organ formation, we performed additional genetic interaction experiments on the notum. Overexpressing Sens with the $v g$-Gal4 induced ectopic formation of numerous bristles on the notum (Fig. 4F). However, coexpressing of the $m i R-9 a$ precursor and Sens largely repressed ectopic bristle formation (Fig. 4G), indicating that $m i R-9 a$ can suppress Sens expression in vivo. In this experiment, the UAS-sens construct contains the sens 3'UTR. The bristle defect was rescued to different degrees with two different UAS-pre-miR-9a transgenic lines (lines \#3 and \#8) (Fig. 4H). As a control, overexpression of the mutant $\operatorname{miR}-9 a$ precursor with a 7-nt deletion failed to rescue the sens overexpression phenotype (Fig. 4H). These data provide further evidence that $m i R-9 a$ and sens function in the same genetic pathway in controlling SOP formation.

\section{miR-9a regulates Sens expression in vivo}

To provide mechanistic insights into the actions of $m i R$ $9 a$ in controlling sensory organ formation, we set out to examine whether the Sens protein level could be affected by $m i R-9 a$ in vivo. In the Drosophila imaginal wing disc, sens is expressed in proneural clusters and accumulates in presumptive SOPs (Nolo et al. 2000). We performed in situ hybridization on the wing discs of third instar larvae and found that miR-9a is widely expressed except for some cells in the wing margins in wild-type flies (Fig. 

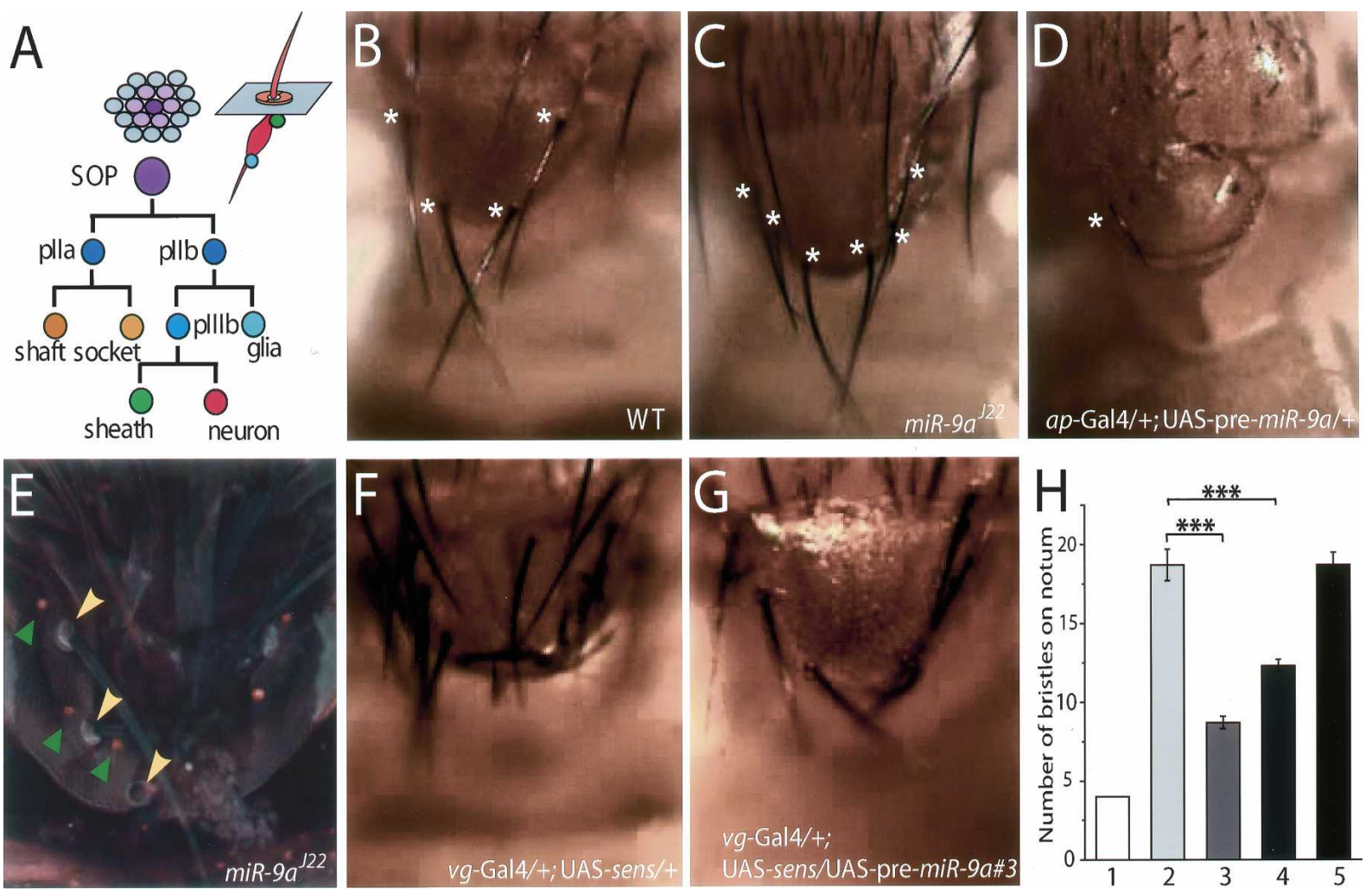

Figure 4. miR-9a mutant flies show a sensory bristle defect on the notum, and miR-9a genetically interacts with sens. (A) Schematic representation of the cell lineage of an adult sensory organ from a single SOP. (B) Wild-type flies have four scutellar bristles (asterisks) on the notum. (C) miR-9a mutant flies have four to seven scutellar bristles on the notum (asterisks). ( $D)$ Overexpression of miR-9a resulted in a loss of scutellar bristles (asterisk indicates the only remaining bristle). (E) In miR-9a mutant flies, all bristles (yellow arrowhead) have normal shaft and socket cells and are accompanied by ELAV ${ }^{+}$sensory neurons (green arrowheads). Some bristles were lost during the staining process. (F) Overexpression of Sens dramatically increased the number of sensory bristles on the notum. (G) Coexpression of $m i R-9 a$ suppressed the generation of ectopic bristles induced by Sens overexpression. $(H)$ Statistical analysis of genetic interactions between sens and miR-9a. Genotypes are as follows: wild-type $(n=50)$ (bar 1$) ; v g-G a l 4 /+; U A S-s e n s /+(n=20)($ bar 2$)$; $v g$-Gal4/+;UAS-sens/UAS-pre-miR-9a (line \#3) $(n=20)$ (bar 3); vg-Gal4/UAS-pre-miR-9a; (line \#8) UAS-sens/+ $(n=20)($ bar 4); and $v g$-Gal4/+;UAS-sens/UAS-mutant-pre-miR-9a $(n=20)\left(\right.$ bar 5). Values are means \pm SEM. $\left(^{\star \star \star}\right) p<0.001$.

5A), but not miR-9a mutants (Fig. 5B). To examine miR$9 a$ expression at the cellular level, we performed in situ hybridization of miR-9a on a A101-Gal4/UAS-mCD8GFP disc in which a subset of SOPs is labeled with GFP (Fig. 5C). Interestingly, miR-9a is not expressed in SOPs, but is expressed in most, if not all, epithelial cells, including the ones adjacent to SOPs (Fig. 5D,E). Sens is dynamically regulated within proneural clusters during SOPs specification: It is up-regulated in SOPs and downregulated in other cells (Nolo et al. 2000). The expression pattern of miR-9a is consistent with the "avoidance hypothesis" that miR-9a may control SOP formation through regulation of gene expression in non-SOP cells (Stark et al. 2005).

To provide direct evidence that miR-9a plays a role in SOP formation by regulating Sens expression, we examined Sens expression in the wing imaginal disc. As shown by immunostaining of wing imaginal discs of wild-type third instar larvae, Sens is first expressed in proneural cluster cells at an early stage and is concentrated in SOPs during SOP specification. Two rows of
Sens ${ }^{+}$cells at the pouch region develop into SOPs in the late third instar stage and into sensory bristles on adult wing margins (Fig. 5F). In the region that develops into the notum, there are two Sens ${ }^{+}$cells, which are the precursors for the two scutellar bristles on each hemi-notum (Fig. 5F, inset). In the miR-9a mutant, there were more SOPs in early third instar wing discs (Fig. 5G), and $>60 \%$ of the discs contained three or four Sens ${ }^{+}$SOPs in the notum region (Fig. 5G, inset). These findings are consistent with the ectopic bristles in adult miR-9a mutant flies (Fig. 4C).

Conversely, overexpression of $m i R-9 a$ in the dorsal compartment of the wing disc by ap-Gal4 (Calleja et al. 1996) significantly reduced the number of Sens ${ }^{+}$cells, and the two SOPs in the notum region were absent (Fig. 5H), consistent with the balding phenotype in adult mutant flies (Fig. 4D). These data provide strong evidence that the ectopic sensory organs in miR-9a mutant flies result from ectopic SOPs during neurogenesis, and that $m i R-9 a$ normally suppresses Sens expression, thereby inhibiting the SOP fate in surrounding epithelial cells. 

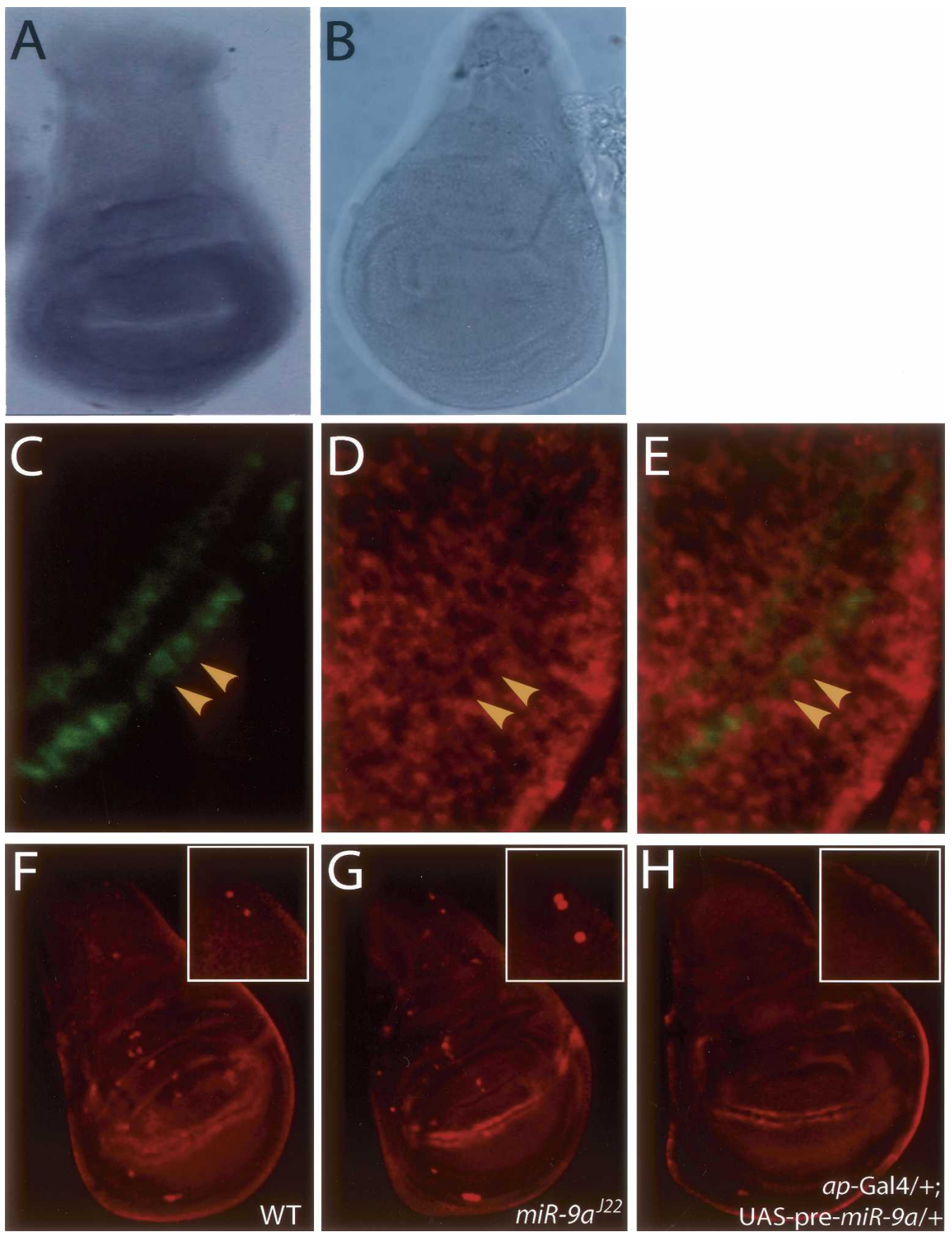

Figure 5. $m i R-9 a$ is expressed in epithelial cells, including cells adjacent to SOPs in wing imaginal discs. $(A)$ miR-9a is ubiquitously expressed in wild-type wing imaginal discs except the wing margins, as shown with a Dig-labeled probe detected with an APconjugated anti-Dig antibody. (B) A miR- $9 a^{J 22}$ mutant wing imaginal disc has no miR-9a expression. $(C-E)$ High-resolution fluorescent in situ hybridization shows that miR-9a is expressed in the epithelial cells, including cells adjacent to the SOPs in the pouch region of a wild-type wing imaginal disc. (C) At the wing margins, SOPs were visualized by mCD8-GFP driven by A101-Gal4 (yellow arrowheads indicate two of them). (D) A Dig-labeled miR-9a probe detected by Cy3-conjugated anti-Dig antibody (red) shows miR-9a is expressed in the epithelial cells, including ones adjacent to the SOPs. (E) Merged image of $C$ and $D$ showing miR-9a is excluded from the SOPs in the wing margins. $(F-H)$ Immunostaining of Sens (red) in wing imaginal discs of early third instar larvae. $(F)$ In the wild-type wing disc, Sens is highly expressed in SOPs and wing margins. Inset shows a magnified view of the notum region from which scutellar bristles are derived. $(G)$ miR- $9 a^{I 22}$ mutant imaginal wing disc has ectopic SOPs. (Inset) A high frequency of extra SOPs was observed in the notum region. $(H)$ When $m i R-9 a$ is overexpressed with ap-Gal4 in the dorsal part of the wing disc, Sens expression was suppressed in most of the dorsal compartment. Inset shows the absence of Sens ${ }^{+}$cells (SOPs) in the region that develops into the notum. 
miR-9a directly suppresses sens expression through its 3'UTR

It was predicted that the sens 3 'UTR contains three $m i R$ 9a-binding sites (Fig. 6A; Stark et al. 2003). To test whether $\operatorname{miR}-9 a$ suppresses Sens expression directly through its 3'UTR, we performed luciferase assays. HEK293 cells were cotransfected with the wild-type miR-9a precursor and sens 3'UTR downstream from the luciferase coding region. The relative luciferase activity was $70 \%$ lower than in cells expressing the luciferasesens 3'UTR alone (Fig. 6C). Two mutant constructs of $\operatorname{miR}-9 a$ precursors were generated as controls, one with a 5 -nt deletion in the mature $m i R-9 a$ region (Mut-1) and one with a 7-nt deletion in the stem of the precursor (Mut-2) (Fig. 6B). Both of these mutant constructs failed to suppress the expression of luciferase with the sens 3'UTR (Fig. 6C). As an additional control, none of the miR-9a constructs had any effect on the expression of luciferase without the sens 3'UTR (data not shown). These findings provide strong evidence that $m i R-9 a$ directly suppresses sens expression through its $3^{\prime} \mathrm{UTR}$.

\section{Discussion}

Drosophila miR-9a suppresses neuronal precursor specification

miR-9 $a$ is one of the miRNAs that are highly expressed in the mammalian brain and $100 \%$ conserved at the nucleotide sequence from flies to humans, suggesting an important role in brain development and/or function (Lagos-Quintana et al. 2002; Aravin et al. 2003; Sempere et al. 2004). We generated miR-9a loss-of-function alleles and found that homozygous mutant flies developed into adulthood at the expected Mendelian ratio. Adult mutant flies are grossly normal and fertile, indicating that $\operatorname{miR}-9 a$ is not required for viability or fertility. This finding is different from the reported severe dorsal closure defects and embryonic lethal phenotype generated by antisense 2'O-methyl oligoribonucleotide-mediated depletion of miR-9a (Leaman et al. 2005).

Interestingly, Drosophila $\mathrm{miR}-9 \mathrm{a}$ is not expressed in mature neurons, but is expressed in epithelial cells, including the proneural clusters that give rise to SOPs (Figs. 2, 5; Stark et al. 2005). Detailed analysis of embryonic PNS development revealed an unexpected finding that $\operatorname{miR}-9 a$ mutants have an increased number of sensory neurons (Fig. 2) that elaborate extensive dendritic arbors underneath the epithelial cell layer, such as ddaE and ddaF neurons (Sweeney et al. 2002). The duplicated neurons occupy the same dendritic field and appear to have similar dendritic branching patterns (Fig. 2C,D). Indeed, the average numbers of dendritic ends of ddaE and $\mathrm{ddaF}$ neurons in abdominal segments $3-5$ were similar in wild-type and miR-9a mutant larvae and MARCM clones (data not shown), indicating that loss of miR-9a activity affected the number of these sensory neurons only but had no cell-autonomous effect on their dendritic branching patterns.

The effect of miR-9a on the number of embryonic sen-

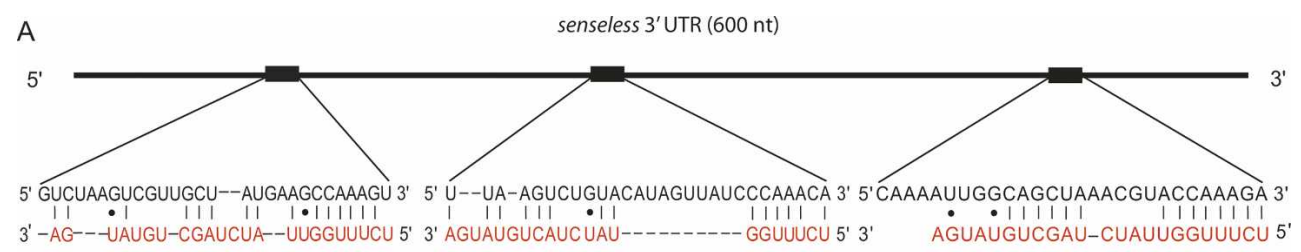

B

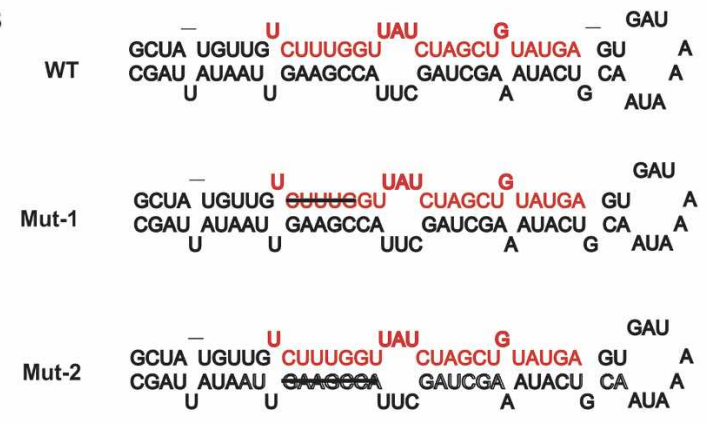

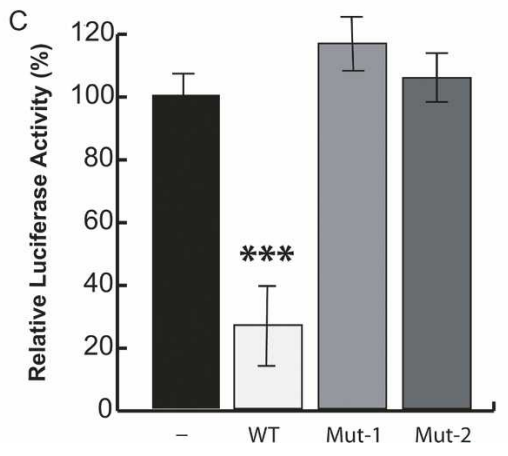

Figure 6. Luciferase assay showing the suppression by miR-9a through the sens $3^{\prime} \mathrm{UTR}$. $(A)$ The sequences and locations of three predicted miR-9a-binding sites in the sens $3^{\prime}$ UTR and their alignment with miR-9a (red). (B) The predicted stem-loop-stem structure of the miR-9a precursor. (WT) Wild-type precursor; (Mut-1) mutant precursor 1 with a 5 -nt deletion in mature miR-9a; (Mut-2) the mutant precursor with a 7-nt deletion in the stem region complementary to mature miR-9a. Mature miR-9a is highlighted in red, and strikethroughs indicate the deleted nucleotides. (C) Wild-type (WT) but not mutant miR-9a precursors (Mut-1 and Mut-2) could suppress the expression of luciferase with the sens $3^{\prime} \mathrm{UTR}$. Bars indicate the average of luciferase activity in one triplicated experiment. $\left({ }^{\star \star \star}\right) p<0.001$. 
sory neurons has two major features. First, the ectopic ddaE or ddaF neurons were generated as a result of ectopic SOPs and not cell fate transformation within a cell lineage (Fig. 2), suggesting miR-9a affects an early step in neurogenesis, consistent with its embryonic expression pattern (Fig. 2; Stark et al. 2005). Second, both the expressivity and penetrance of this defect were relatively low. This finding supports the idea that miRNAs, at least in this particular case, are not developmental switches, but instead function as a fine-tuning mechanism to ensure the accuracy of a particular developmental process (e.g., Farh et al. 2005; Stark et al. 2005).

In this study, we focused on the formation of SOPs in adult flies. Like embryos, only $\sim 14 \%$ of $m i R-9 a$ mutant flies exhibited ectopic SOPs on the notum, again indicating a fine-tuning role for $m i R-9 a$ in controlling SOP formation. However, our analysis of the $m i R-9 a$ mutant phenotype in adult flies also indicates that miRNAs can have dramatic effects on some other developmental processes. For instance, $m i R-9 a$ is widely expressed in the wing disc (Fig. 5), and 100\% of miR-9a mutant flies exhibited a severe posterior wing margin defect (Fig. 3), suggesting that cell proliferation and/or survival are much more sensitive to changes in the expression levels of the proteins regulated by $\operatorname{miR}-9 a$.

\section{MiR-9a inhibits Sens expression in non-SOP cells}

How does miR-9a exert its effect on SOP formation? Sens is a zinc finger transcription factor required to maintain high-level expression of proneural gene in SOPs and to suppress their expression in non-SOP cells (Nolo et al. 2000; Jafar-Nejad et al. 2003). Several findings in this study demonstrate that Sens is a key target of $m i R-9 a$ regulation and is essential for mediating $m i R-9 a$ function in SOP formation. (1) The wing margin defects in $\operatorname{miR}-9 a$ mutant flies were remarkably similar to that caused by overexpression of Sens by the UAS-Gal4 system or in Lyra $^{1}$ mutants (Nolo et al. 2000, 2001). (2) $\operatorname{miR}-9 a$ was expressed at a much lower level in SOPs than in adjacent epithelial cells, correlating with the high level of Sens expression in SOPs and the low level of Sens in non-SOP cells in proneural clusters. The inability to use immunostaining to detect subtle changes of Sens expression level in non-SOP cells due to $\mathrm{miR}-9 a$ loss of function could be attributed to the following reasons: Sens expression is primarily down-regulated at the transcriptional level in the non-SOP proneural cells, and $m i R-9 a^{\prime}$ s function is limited to preventing translation of the leaky/residual sens mRNA, consistent with the model proposed by Stark et al. (2005). The alteration in

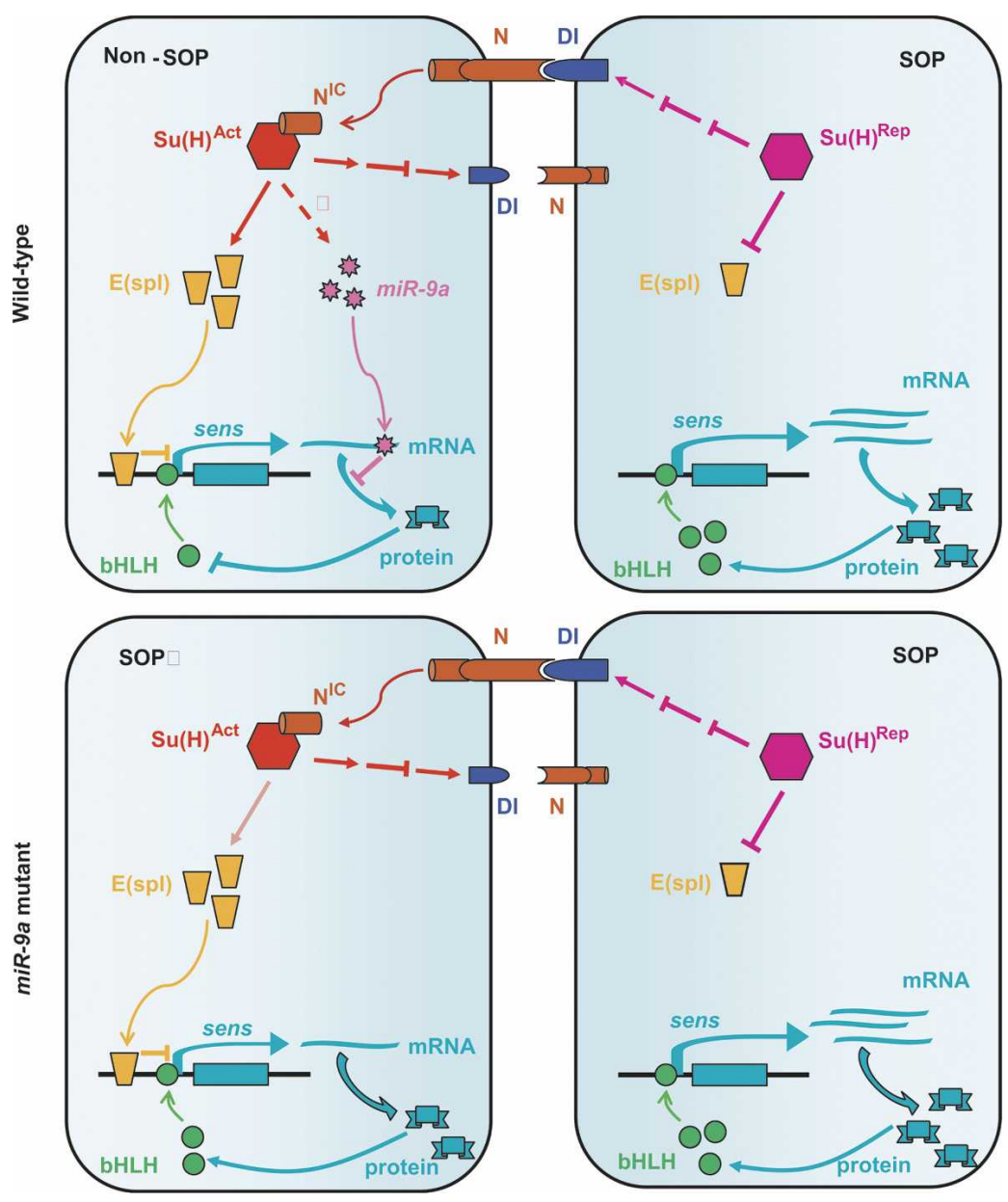

Figure 7. A model for the role of miR-9a in regulating SOP specification. Within one proneural cluster, the cell selected to become the SOP expresses a high level of Delta to activate Notch in the adjacent cells (non-SOPs). Upon activation, Notch releases the intracellular domain $\left(\mathrm{N}^{\mathrm{IC}}\right)$, which translocates to nuclei and binds to Suppressor of Hairless, switching it to the active form $\left[\mathrm{Su}(H)^{\mathrm{Act}}\right]$. The $\mathrm{N}^{\mathrm{IC}} / \mathrm{Su}(H)^{\text {Act }}$ complex activates Enhancer of Split [E(spl)], and consequently represses sens transcription. In SOPs, without the activation of Notch, $\mathrm{Su}(H)$ functions as a repressor $\left[\mathrm{Su}(H)^{\mathrm{Rep}}\right]$ to suppress the E(spl). Therefore, sens could be continuously transcribed, allowing high-level accumulation of Sens protein, which is required for further transcription of neuron-specific genes. $\mathrm{miR}-9 a$ functions in non-SOP cells to further suppress Sens translation through its $3^{\prime}$ UTR to ensure the precise production of SOPs. 
Sens level, due to loss of miR-9a function in the nonSOP cells, is sufficient to initiate the production of ectopic SOPs, but it may not be dramatic enough to be detected by immunostaining. (3) The sens 3'UTR contains three $m i R$ - $9 a$-binding sites and is the best predicted target of miR-9a (Stark et al. 2003). (4) Wild-type but not mutant miR-9a precursors down-regulated reporter gene expression through the sens 3'UTR in transfected cells. (5) Overexpression of miR-9a in vivo inhibited Sens expression. We observed that Sens expression along the wing margin in the dorsal compartment was lower than in the ventral compartment in some wing discs when miR-9a was expressed by $a p$-Gal4 (data not shown). The failure to completely suppress Sens expression in the dorsal compartment (Fig. $5 \mathrm{H}$ ) is probably due to the fact that, at this developmental stage, Sens expression in the wing margins is controlled by proneural genes, unlike SOPs in the notum region where Sens expression is maintained by itself (Jafar-Nejad et al. 2003). (6) miR-9a and sens showed strong genetic interactions in controlling SOP formation.

These findings provide an experimental example to support the notion that miRNAs and their mRNA targets are often expressed in cells adjacent to each other (Stark et al. 2005). The differential expression of Sens in SOPs and adjacent neuroepithelial cells is essential for the production of a precise number of SOPs during development (Nolo et al. 2000; Jafar-Nejad et al. 2003). We propose a model in which miR-9a functions in non-SOPs cells to further suppress Sens expression at the translational level, as a complementary mechanism to the transcriptional inhibition of Sens expression by E(spl) (Fig. 7). Loss of $m i R-9 a$ function increases Sens protein level, not so dramatically but just enough to convert Sens in some neuroepithelial cells from a transcription repressor into an activator of proneural genes, therefore resulting in the formation of a small number of ectopic SOPs. However, unlike many other genes essential for neurogenesis, such as Notch and Delta, miR-9a does not function as an absolute switch. Instead, it only ensures the accurate differential Sens expression and fine-tunes this developmental process.

Overexpression of $m i R-9 a$ in the wing imaginal disc could dramatically inhibit the formation of sensory organs on the notum (Fig. 4D), suggesting that misregulation of miR-9a expression itself could potentially have severe developmental consequences. Since both miR-9a and $\mathrm{E}(\mathrm{spl})$ have similar functions in non-SOP cells, it is possible that both genes may be regulated by a similar transcriptional mechanism. Indeed, we noticed that binding sites for the Achaete-Scute complex and $\mathrm{Su}(\mathrm{H})$ are present in the regulatory region of miR-9a. Taken together, our studies presented here have uncovered another layer of gene regulation during early neurogenesis in the Drosophila PNS. miR-9a is $100 \%$ conserved at the nucleotide level from flies to humans. Moreover, the human miR-9a is highly expressed in fetal but not in adult brains (Nelson et al. 2006). Therefore, a similar mechanism of miR-9a function may operate during mammalian neurogenesis as well.

\section{Materials and methods}

Fly strains and genetics

All the flies were maintained at $22^{\circ} \mathrm{C}-25^{\circ} \mathrm{C}$ on standard medium. The $w^{1118}$ strain was used as a wild-type control. Gal4 ${ }^{221}$ combined with UAS-mCD8::GFP was used to visualize individual $\mathrm{ddaE}$ and ddaF neurons in the larval PNS. It was recombined with miR-9a mutants to generate the homozygous stock Gal4221, UAS-mCD8::GFP, miR-9a. For studies of the wing and the notum, the following lines were used: $v g$-Gal4, $a p$-Gal4 (Calleja et al. 1996), and UAS-sens (Nolo et al. 2000). The presence of sens $3^{\prime}$ UTR in the UAS-sens construct was confirmed by PCR. sens ${ }^{E 58}$ was used as the sens loss-of-function mutant allele in genetic interaction experiments.

\section{Target homologous recombination constructs}

miR-9a loss-of-function mutations were generated with the ends-out technology (Gong and Golic 2003). The targeting construct contains the $W^{+}$gene flanked by two arms of genomic DNA fragments at the miR-9a locus. The two arms were prepared by PCR from the genomic DNA using primers 5'-AGCGATCGTCGTCGGACTAC- ${ }^{\prime}$ ' and 5' -ACACTGCAGATGGTTGAAAG-3' for the left arm, and primers 5'-ACTCGAGCCAAAAACGAGGCCCACA- ${ }^{\prime}$ ' and $5^{\prime}$-AGGTACCGAGACAG CAAAATCGTAGAA-3' for the right arm. Two independent transgenic fly lines carrying the targeting construct were crossed to hs-FLP, I-SceI (Bloomington Stock Center), and the progenies at late second to third instar stages were heat-shocked for $45 \mathrm{~min}$ at $38^{\circ} \mathrm{C}$. Virgin female flies with mosaic eyes were collected and crossed to p $\{70 F L P\} 10$ (Bloomington Stock Center), and at the next generation, individual males with solidcolor eyes were crossed to TM3 Ser/TM6 Tb as candidate lines. For the replacement of the miR-9a by $w^{+}$, a PCR screen was performed with genomic DNAs isolated from each line. Northern blot was used to confirm the absence of $m i R-9 a$ expression in mutant flies.

\section{Transgenic constructs}

The 78-base-pair (bp) miR-9a precursor was cloned from wildtype genomic DNA with primers 5'-GAATTCTATACAGGGTGCTATGTTG-3' and 5'-TCTAGACGCTGGGCAGACGCTAATATTAACTTCGG-3'. The mutant precursor with a 7-bp deletion on the stem was generated with primers $5^{\prime}$-GAATTCTATACAGGGTGCTATGTTG- $3^{\prime}$ and 5'-TCTAGACGCT GGCAGACGCTAATATTAAAAGCTAGCTTTATGACGT-3'. Both fragments were subcloned into the pUAST vector and injected into embryos to generate transgenic fly stocks that express either wild-type or mutant $m i R-9 a$ precursor under the control of UAS elements.

\section{Northern blot}

Total RNA was extracted from larvae with Trizol, according to the manufacturer's instructions (Invitrogen). For each sample, $20 \mu \mathrm{g}$ of total RNA was run on a $12 \%$ polyacrylamide gel (Sequagel, National Diagnostics) and transferred to a Nytran SuperCharge Signal membrane (Schleicher \& Schuell). miR-9a was detected with a purified ${ }^{32} \mathrm{P}$-end-labeled oligo probe, $5^{\prime}$ TCATACAGCTAGATAACCAAAGA-3', which is complementary to the mature miR-9a sequence.

\section{In situ hybridization}

Embryos and wing imaginal discs were fixed and stained according to standard procedures (Tautz and Pfeifle 1989). A genomic 
fragment of $1 \mathrm{~kb}$ flanking the $m i R-9 a$ precursor was obtained by PCR and cloned into the pBSK vector. A Digoxigenin (Dig)labeled riboprobe was generated by in vitro transcription of this construct with T7 RNA polymerase. A Drosophila miR-9a locked nucleic acid (LNA) probe was obtained from Exiqon (Vedbaek), end-labeled with a Dig oligonucleotide 3'-end-labeling kit (Roche), and purified on a G-25 Microspin column (Amersham Biosciences). In situ hybridization with both probes was detected by AP-conjugated cy3-conjugated anti-Dig antibody according to standard procedures (Tautz and Pfeifle 1989) with the following modifications: After post-fixation and washes, the discs were washed with water and treated twice for 5 min each with $0.25 \%(\mathrm{v} / \mathrm{v})$ acetic anhydride in $0.1 \mathrm{M}$ triethanolamine $(\mathrm{pH}$ 8.0). The tissues were prehybridized and hybridized at $50^{\circ} \mathrm{C}$ in hybridization buffer ( $\mathrm{pH}$ 6.0, adjusted with citric acid).

\section{Antibody staining}

Embryos were fixed according to the standard protocol. Third instar larval wing imaginal discs were fixed in $4 \%$ formaldehyde in PBT (PBS and $0.1 \%$ Triton X-100) for $30 \mathrm{~min}$ at room temperature. Pupae were dissected $48 \mathrm{~h}$ after pupa formation and fixed in $4 \%$ formaldehyde in PBT overnight at $4^{\circ} \mathrm{C}$. The following pairs of primary and secondary antibodies were used for all experiments: anti-Sens (1:1000) (Nolo et al. 2000) and antiguinea pig-Cy3 (1:500; Molecular Probes); anti-ELAV (1:100; Developmental Hybridoma Study Bank) and anti-mouse-Cy3 or anti-mouse-FITC (1:300; Jackson Laboratory); anti-Cut (1:1000; Developmental Hybridoma Study Bank) and anti-rabbit-Cy3 (1:300; Jackson Laboratory).

\section{Microscopy and imaging}

All samples with fluorescent signals were imaged by confocal microscopy (Nikon, D-Eclipse C1), including GFP-labeled DA neurons in third instar larvae; immunostaining on embryos, wing discs, and the pupa notum; and fluorescence-labeled in situ hybridization on wing discs. Images of adult wing and notum and Dig-labeled in situ hybridization on wing discs were obtained with an Olympus BX60 microscope and AxioCam Hrc camera.

\section{Luciferase reporter assays}

The wild-type and two mutant $\operatorname{miR}-9 a$ precursors were obtained by PCR and cloned into the pSUPER vector under the control of the $\mathrm{H} 1$ promoter (OligoEngine). A 600-bp fragment of the sens 3'UTR was cloned into the pGL3-promoter vector (Promega) downstream from the firefly luciferase gene. The Renilla luciferase plasmid served as the transfection control. HEK293 cells were cotransfected in 12 -well plates with three vectors $\mid 0.5$ $\mu \mathrm{g}$ of each vector per well): the luciferase-sens 3'UTR reporter plasmid, the Renilla luciferase plasmid, and the pSUPER vector containing miR-9a precursor (wild type, Mut-1, or Mut-2) or the vector only. Three independent transfections with triplicates each time were performed, and cell lysates were collected $28 \mathrm{~h}$ after transfection. Relative luciferase activity was measured with Dual-luciferase assays (Promega) according to the manufacturer's protocol.

\section{Acknowledgments}

We thank H. Bellen, the Bloomington Stock Center, and the Developmental Hybridoma Bank for reagents and fly lines. We thank S. Ordway and G. Howard for editorial assistance, K.
Nyuyen for manuscript preparation, and L.-P. Chang for help with the UAS-pre-miR-9a construct. We also thank T. Kornberg, Y. Hong, and laboratory members for discussions and comments during the course of this work. This study was supported by an NIH training grant (T32 AG00278 to F.W.), the Korea Research Foundation (KRF: M01-2005-000-10157-0 to J.L.), and the Esther A. and Joseph Klingenstein Fund, the McKnight Endowment Fund for Neuroscience, FRAXA Foundation, Pfizer/ AFAR, and the NIH (to F.-B.G.).

\section{References}

Ainsley, J.A., Pettus, J.M., Bosenko, D., Gerstein, C.E., Zinkevich, N., Anderson, M.G., Adams, C.M., Welsh, M.J., and Johnson, W.A. 2003. Enhanced locomotion caused by loss of the Drosophila DEG/ENaC protein Pickpocket1. Curr. Biol. 13: $1557-1563$.

Alvarez-Garcia, I. and Miska, E.A. 2005. MicroRNA functions in animal development and human disease. Development 132: 4653-4662.

Aravin, A.A., Lagos-Quintana, M., Yalcin, A., Zavolan, M., Marks, D., Snyder, B., Gaasterland, T., Meyer, J., and Tuschl, T. 2003. The small RNA profile during Drosophila melanogaster development. Dev. Cell 5: 337-350.

Artavanis-Tsakonas, S., Rand, M.D., and Lake, R.J. 1999. Notch signaling: Cell fate control and signal integration in development. Science 284: 770-776.

Bardin, A.J., Le Borgne, R., and Schweisguth, F. 2004. Asymmetric localization and function of cell-fate determinants: A fly's view. Curr. Opin. Neurobiol. 14: 6-14.

Bartel, D.P. 2004. MicroRNAs: Genomics, biogenesis, mechanism, and function. Cell 116: 281-297.

Bodmer, R. and Jan, Y.N. 1987. Morphological differentiation of the embryonic peripheral neurons in Drosophila. Rouxs Arch. Dev. Biol. 196: 69-77.

Brennecke, J., Hipfner, D.R., Stark, A., Russell, R.B., and Cohen, S.M. 2003. bantam encodes a developmentally regulated microRNA that controls cell proliferation and regulates the proapoptotic gene hid in Drosophila. Cell 113: 25-36.

Brewster, R. and Bodmer, R. 1995. Origin and specification of type II sensory neurons in Drosophila. Development 121: 2923-2936.

Calleja, M., Moreno, E., Pelaz, S., and Morata, G. 1996. Visualization of gene expression in living adult Drosophila. Science 274: 252-255.

Campos-Ortega, J.A. and Hartenstein, V. 1985. The embryonic development of Drosophila melanogaster. Springer-Verlag, Heidelberg, New York, Tokyo.

Carrington, J.C. and Ambros, V. 2003. Role of microRNAs in plant and animal development. Science 301: 336-338.

Carthew, R.W. 2006. Gene regulation by microRNAs. Curr. Opin. Genet. Dev. 16: 203-208.

Caudy, A.A., Myers, M., Hannon, G.J., and Hammond, S.M. 2002. Fragile X-related protein and VIG associate with the RNA interference machinery. Genes \& Dev. 16: 2491-2496.

Chang, S., Johnston Jr., R.J., Frokjaer-Jensen, C., Lockery, S., and Hobert, O. 2004. MicroRNAs act sequentially and asymmetrically to control chemosensory laterality in the nematode. Nature 430: 785-789.

Cubas, P., de Celis, J.F., Campuzano, S., and Modolell, J. 1991. Proneural clusters of achaete-scute expression and the generation of sensory organs in the Drosophila imaginal wing disc. Genes \& Dev. 5: 996-1008.

Farh, K.K.-W., Grimson, A., Jan, C., Benjamin, P., Lewis, B.P., Wendy, K., Johnston, W.K., Lim, L.P., Christopher, B., Burge, 
C.B., et al. 2005. The widespread impact of mammalian microRNAs on mRNA repression and evolution. Science 310: $1817-1821$.

Gao, F.-B., Brenman, J.E., Jan, L.Y., and Jan, Y.N. 1999. Genes regulating dendritic outgrowth, branching, and routing in Drosophila. Genes \& Dev. 13: 2549-2561.

Ghysen, A. and Dambly-Chaudiere, C. 1993. The specification of sensory neuron identity in Drosophila. Bioessays 15: 293298

Ghysen, A., Dambly-Chaudiere, C., Aceves, E., Jan, L.Y., and Jan, Y.N. 1986. Sensory neurons and perihperal pathways in Drosophila embryos. Rouxs Arch. Dev. Biol. 195: 281-289.

Giraldez, A.J., Cinalli, R.M., Glasner, M.E., Enright, A.J., Thomson, J.M., Baskerville, S., Hammond, S.M., Bartel, D.P., and Schier, A.F. 2005. MicroRNAs regulate brain morphogenesis in zebrafish. Science 308: 833-838.

Gong, W.J. and Golic, K.G. 2003. Ends-out, or replacement, gene targeting in Drosophila. Proc. Natl. Acad. Sci. 100: 2556-2561.

Goriely, A., Dumont, N., Dambly-Chaudiere, C., and Ghysen, A. 1991. The determination of sense organs in Drosophila: Effect of the neurogenic mutations in the embryo. Development 113: 1395-1404.

Goulding, S.E., zur Lage, P., and Jarman, A.P. 2000. amos, a proneural gene for Drosophila olfactory sense organs that is regulated by lozenge. Neuron 25: 69-78.

Grueber, W.B., Jan, L.Y., and Jan, Y.N. 2002. Tiling of the Drosophila epidermis by multidendritic sensory neurons. Development 129: 2867-2878.

Hartenstein, V. and Posakony, J.W. 1989. Development of adult sensilla on the wing and notum of Drosophila melanogaster. Development 107: 389-405.

He, L. and Hannon, G.J. 2004. MicroRNAs: Small RNAs with a big role in gene regulation. Nat. Rev. Genet. 5: 522-531.

Huang, M.L., Hsu, C.H., and Chien, C.T. 2000. The proneural gene amos promotes multiple dendritic neuron formation in the Drosophila peripheral nervous system. Neuron 25: 57-67.

Ishizuka, A., Siomi, M.C., and Siomi, H. 2002. A Drosophila fragile X protein interacts with components of RNAi and ribosomal proteins. Genes \& Dev. 16: 2497-2508.

Jafar-Nejad, H., Acar, M., Nolo, R., Lacin, H., Pan, H., Parkhurst, S.M., and Bellen, H.J. 2003. Senseless acts as a binary switch during sensory organ precursor selection. Genes \& Dev. 17: 2966-2978.

Jan, Y.N. and Jan, L.Y. 1993. HLH proteins, fly neurogenesis, and vertebrate myogenesis. Cell 75: 827-830.

Jarman, A.P., Brand, M., Jan, L.Y., and Jan, Y.N. 1993. The regulation and function of the helix-loop-helix gene, asense, in Drosophila neural precursors. Development 119: 19-29.

Johnston, R.J. and Hobert, O. 2003. A microRNA controlling left/right neuronal asymmetry in Caenorhabditis elegans. Nature 426: 845-849.

Knust, E., Schrons, H., Grawe, F., and Campos-Ortega, J.A. 1992. Seven genes of the Enhancer of split complex of Drosophila melanogaster encode helix-loop-helix proteins. Genetics 132: 505-518.

Krichevsky, A.M., Sonntag, K.-C., Isacson, O., and Kosik, K.S. 2006. Specific MicroRNAs modulate embryonic stem cellderived neurogenesis. Stem Cells 24: 857-864.

Kwon, C., Han, Z., Olson, E.N., and Srivastava, D. 2005. MicroRNA1 influences cardiac differentiation in Drosophila and regulates Notch signaling. Proc. Natl. Acad. Sci. 102: 18986-18991.

Lagos-Quintana, M., Rauhut, R., Yalcin, A., Meyer, J., Lendeckel, W., and Tuschl, T. 2002. Identification of tissue-specific microRNAs from mouse. Curr. Biol. 12: 735-739.

Leaman, D., Chen, P.Y., Fak, J., Yalcin, A., Pearce, M., Unner- stall, U., Marks, D.S., Sander, C., Tuschl, T., and Gaul, U 2005. Antisense-mediated depletion reveals essential and specific functions of microRNAs in Drosophila development. Cell 121: 1097-1108.

Lee, T. and Luo, L. 1999. Mosaic analysis with a repressible cell marker for studies of gene function in neuronal morphogenesis. Neuron 22: 451-461.

Lee, A., Li, W., Xu, K., Bogert, B.A., Su, K., and Gao, F.-B. 2003 Control of dendritic development by the Drosophila fragile $\mathrm{X}$-related gene involves the small GTPase Rac1. Development 130: 5543-5552.

Li, X. and Carthew, R.W. 2005. A microRNA mediates EGF receptor signaling and promotes photoreceptor differentiation in the Drosophila eye. Cell 123: 1267-1277.

Liu, L., Yermolaieva, O., Johnson, W.A., Abboud, F.M., and Welsh, M.J. 2003. Identification and function of thermosensory neurons in Drosophila larvae. Nat. Neurosci. 6: 267273.

Modolell, J. 1997. Patterning of the adult peripheral nervous system of Drosophila. Perspect. Dev. Neurobiol. 4: 285-296.

Nelson, P.T., Baldwin, D.A., Kloosterman, W.P., Kauppinen, S., Plasterk, R.H., and Mourelatos, Z. 2006. RAKE and LNAISH reveal microRNA expression and localization in archival human brain. RNA 12: 187-191

Nolo, R., Abbott, L.A., and Bellen, H.J. 2000. Senseless, a Zn finger transcription factor, is necessary and sufficient for sensory organ development in Drosophila. Cell 102: 349-362.

Nolo, R., Abbott, L.A., and Bellen, H.J. 2001. Drosophila Lyra mutations are gain-of-function mutations of senseless. Genetics 157: 307-315

Romani, S., Campuzano, S., Macagno, E.R., and Modolell, J. 1989. Expression of achaete and scute genes in Drosophila imaginal discs and their function in sensory organ development. Genes \& Dev. 3: 997-1007.

Ruiz-Gomez, M. and Ghysen, A. 1993. The expression and role of a proneural gene, achaete, in the development of the larval nervous system of Drosophila. EMBO J. 12: 1121-1130.

Schratt, G.M., Tuebing, F., Nigh, E.A., Kane, C.G., Sabatini, M.E., Kiebler, M., and Greenberg, M.E. 2006. A brain-specific microRNA regulates dendritic spine development. $\mathrm{Na}$ ture 439: 283-289.

Schweisguth, F. and Posakony, J.W. 1992. Suppressor of Hairless, the Drosophila homolog of the mouse recombination signal-binding protein gene, controls sensory organ cell fates. Cell 69: 1199-1212.

Sempere, L.F., Freemantle, S., Pitha-Rowe, I., Moss, E., Dmitrovsky, E., and Ambros, V. 2004. Expression profiling of mammalian microRNAs uncovers a subset of brain-expressed microRNAs with possible roles in murine and human neuronal differentiation. Genome Biol. 5: R13.

Skeath, J.B. and Carroll, S.B. 1991. Regulation of achaete-scute gene expression and sensory organ pattern formation in the Drosophila wing. Genes \& Dev. 5: 984-995.

Sokol, N.S. and Ambros, V. 2005. Mesodermally expressed Drosophila microRNA-1 is regulated by Twist and is required in muscles during larval growth. Genes \& Dev. 19: 2343-2354.

Stark, A., Brennecke, J., Russell, R.B., and Cohen, S.M. 2003. Identification of Drosophila MicroRNA targets. PLOS Biol. 1: E60

Stark, A., Brennecke, J., Bushati, N., Russell, R.B., and Cohen, S.M. 2005. Animal MicroRNAs confer robustness to gene expression and have a significant impact on 3'UTR evolution. Cell 123: 1133-1146.

Sweeney, N.T., Li, W., and Gao, F.B. 2002. Genetic manipulation of single neurons in vivo reveals specific roles of flamingo in neuronal morphogenesis. Dev. Biol. 247: 76-88. 
Tautz, D. and Pfeifle, C. 1989. A non-radioactive in situ hybridization method for the localization of specific RNAs in Drosophila embryos reveals translational control of the segmentation gene hunchback. Chromosoma 98: 81-85.

Teleman, A.A., Maitra, S., and Cohen, S.M. 2006. Drosophila lacking microRNA miR-278 are defective in energy homeostasis. Genes \& Dev. 20: 417-422.

Tracey Jr., W.D., Wilson, R.I., Laurent, G., and Benzer, S. 2003. painless, a Drosophila gene essential for nociception. Cell 113: 261-273.

Vervoort, M., Merritt, D.J., Ghysen, A., and Dambly-Chaudiere, C. 1997. Genetic basis of the formation and identity of type I and type II neurons in Drosophila embryos. Development 124: 2819-2828.

Vo, N., Klein, M.E., Varlamova, O., Keller, D.M., Yamamoto, T., Goodman, R.H., and Impey, S. 2005. A cAMP-response element binding protein-induced microRNA regulates neuronal morphogenesis. Proc. Nat1. Acad. Sci. 102: 16426-16431.

Xu, P., Vernooy, S.Y., Guo, M., and Hay, B.A. 2003. The Drosophila microRNA Mir-14 suppresses cell death and is required for normal fat metabolism. Curr. Biol. 29: 790-795. 


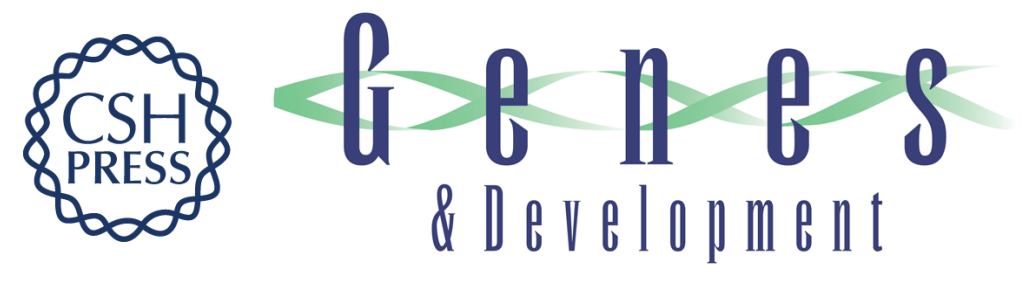

\section{MicroRNA-9a ensures the precise specification of sensory organ precursors in Drosophila}

Yan Li, Fay Wang, Jin-A Lee, et al.

Genes Dev. 2006, 20: originally published online October 2, 2006

Access the most recent version at doi:10.1101/gad.1466306

\section{Supplemental http://genesdev.cshlp.org/content/suppl/2006/10/03/gad.1466306.DC1 \\ Material}

Related Content

Denoising feedback loops by thresholdinga new role for microRNAs

Stephen M. Cohen, Julius Brennecke and Alexander Stark

Genes Dev. October , 2006 20: 2769-2772

References This article cites 56 articles, 23 of which can be accessed free at:

http://genesdev.cshlp.org/content/20/20/2793.full.html\#ref-list-1

Articles cited in:

http://genesdev.cshlp.org/content/20/20/2793.full.html\#related-urls

\section{License}

Email Alerting

Service

Receive free email alerts when new articles cite this article - sign up in the box at the top right corner of the article or click here.

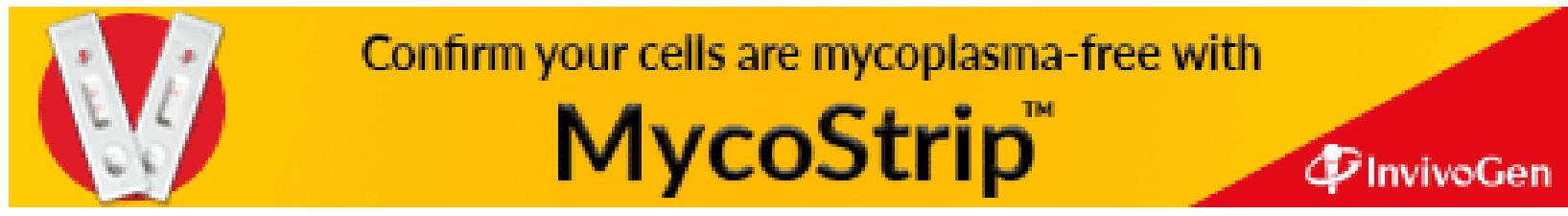

